Communications in Physics, Vol. 27, No. 3 (2017), pp. 245-254

DOI:10.15625/0868-3166/27/3/10661

\title{
PREPARATION OF NiPt ALLOYS BY GALVANIC REPLACEMENT REACTION ON Ni FIMLS FOR DIRECT ETHANOL FUEL CELL
}

\author{
PHAM VAN VINH ${ }^{\dagger}$ \\ Faculty of Physics, Hanoi National University of Education, \\ 136 Xuan Thuy, Cau Giay, Hanoi, Vietnam \\ ${ }^{\dagger} E$-mail: vinhpv@hnue.edu.vn \\ Received 09 August 2017 \\ Accepted for publication 31 August 2017 \\ Published 19 September 2017
}

\begin{abstract}
NiPt alloys were prepared successfully by galvanic replacement reaction on the surface of Ni films. The electrolytic deposition of Ni films was investigated to get the high qualities of Ni films for the galvanic reaction. The influence of the electrolytic currents on the morphology and thickness of Ni films were observed by SEM. The thickness and roughness of the Ni films increase with the increase in electrolytic currents. XRD patterns showed that Ni films were formed in the crystal phase of Ni corresponding to face-centered cubic structure. Pure Ni films obtained by annealing the films in hydrogen medium were used to prepare NiPt alloys due to galvanic reaction of $\mathrm{Pt}^{2+}$ with $\mathrm{Ni}^{2+}$ in $\mathrm{H}_{2} \mathrm{PtCl}_{6}$ solution. The influence of the $\mathrm{H}_{2} \mathrm{PtCl}_{6}$ solution concentration on the composition of NiPt alloys were investigated by EDX. The results of analyses showed that NiPt alloy formed by using high solution concentration of $\mathrm{H}_{2} \mathrm{PtCl}_{6}$ has high composition of Pt. The electrocatalytic activities of both Ni films and NiPt alloys toward ethanol oxidation in $\mathrm{KOH}$ medium were carried out by the cyclic voltammetry measurement. Alloyed samples exhibited high electrocatalytic activities due to carbonaceous removal and weakening Pt-CO ads bond.
\end{abstract}

Keywords: galvanic replacement, NiPt alloy nanoparticles, electrolysis deposition, ethanol oxidation, direct fuel cell.

Classification numbers: 82.47.Pm; 81.10.Dn; 81.15.Pq; 82.45.Aa; 82.45.Jn.

(C)2017 Vietnam Academy of Science and Technology 


\section{INTRODUCTION}

Nowadays, the devices using batteries such as mobile phones, laptops, and other measurement instruments have become more and more popular. The rechargeable batteries have been used for a long time. However, this type of batteries requires charging from an external power source with a long charging time. This is a big challenge for producers to develop the devices further. Fuel cells promise to be next generation batteries that are environment friendly, with high efficiency and long life-time [1]. In nature, fuel cells convert chemical energy to electrical energy directly through the redox reaction of hydrogen and oxygen. Pure hydrogen can be used as fuel source but storing and transporting hydrogen are complicated. For the applications of portable devices, direct ethanol fuel cells (DEFCs) are a good selection for solving this problem $[2,3]$.

To convert chemical energy to electric energy, platinum has been used as a catalyst for ethanol oxidation reaction in DEFCs [4-7]. However, platinum is an expensive material and causes $\mathrm{CO}$ generation during catalytic process. $\mathrm{CO}$ is easy to absorb on $\mathrm{Pt}$ by sharing their electrons in the 5s orbit to $\mathrm{Pt}$ to form the $\mathrm{Pt}-\mathrm{CO}_{a d s}$ bond [8]. $\mathrm{CO}_{a d s}$ can poison an electrode, resulting in reducing the electrocatalytic activities $[9,10]$. To overcome the poisonous problems, alloying platinum with other metals such as $\mathrm{Cu}, \mathrm{Ni}, \mathrm{Sn}, \mathrm{Ag}$... is desired to use. In this case, the $\mathrm{CO}_{a d s}$ can be removed by the reaction of the added metals with $\mathrm{CO}_{a d s}$ to form $\mathrm{CO}_{2}$, resulting in speeding up the ethanol oxidation reaction. Indeed, the studies of ethanol oxidation activities showed that $\mathrm{PtCu}$ electrocatalyst exhibited about 2- fold higher power density than that of the benchmark $\mathrm{Pt} / \mathrm{C}$ [11]; $\mathrm{PtNi}_{3} / \mathrm{MWNTs}$ nanocatalyst had current for the forward anodic peak in EOR about 2.5 times higher than that of pure Pt/MWNTs [12]; study of PtSn alloys prepared by different methods showed an improvement of electrocatalyst ability of PtSn for ethanol oxidation reaction [13].

In previous works, we synthesized successfully NiPt alloy nanoparticles by galvanic re-

placement method using Ni nanoparticles as the templates [14]. Although their electrocatalyst activities toward ethanol oxidation reaction were interesting, it was difficult to control the formation of Ni nanoparticles by replacement method because $\mathrm{NaBH}_{4}$ (a strong reductant) used in these experiments was easy to hydrolyze to form unexpected productions instead of Ni nanoparticles. In this work, we show a simple way to prepare NiPt alloys by galvanic replacement using Ni films that were deposited by an electrolyser instead of Ni nanoparticles.

\section{EXPERIMENTAL}

\section{Preparation of Ni films}

Ni films were deposited on carbon sheet substrates (anode) by an electrolyser using platinum as a cathode. An electrolyte solution was prepared by dissolving $3.30 \mathrm{~g}$ of $\mathrm{NiSO}_{4} .6 \mathrm{H}_{2} \mathrm{O}$, $0.04 \mathrm{~g}$ of $\mathrm{NiCl}_{2} .4 \mathrm{H}_{2} \mathrm{O}$ and $0.03 \mathrm{~g}$ of $\mathrm{H}_{3} \mathrm{BO}_{3}$ in $100 \mathrm{ml} \mathrm{DI}$ water. The influence of electrolytic currents on morphology and thickness of the films was determined by varying current for each deposition.

\section{Preparation of NiPt alloys}

Selected Ni films were annealed in hydrogen medium to reduce oxygen remaining on the samples. After that, annealed samples were in turn immersed in to $\mathrm{H}_{2} \mathrm{PtCl}_{6}$ solution $0.1 \mathrm{M}$ and $0.3 \mathrm{M}$ for $1 \mathrm{~h}$. Finally, the samples were washed by DI water and dried in air for further study. 


\section{Preparation of electrode for cyclic voltammetry measurement}

The films of $\mathrm{Ni}$ and NiPt on the carbon substrates were cut into square shape with the size of $1 \mathrm{~mm}^{2}$. The back side (carbon side) of sample was attached with a copper electrode wire by silver glue. Both the carbon side and the electrode were isolated from the electrolytic solution during the measurement by a layer of epoxy. The cyclic voltammetry measurement was used to evaluate the ethanol oxidation activities of samples. The measurements were carried out in mixed solution containing $2 \mathrm{M} \mathrm{KOH}$ and $1 \mathrm{M}$ ethanol with sweep rate of $50 \mathrm{mVs}^{-1}$ and the voltage range from $-0.80 \mathrm{~V}$ to $+0.60 \mathrm{~V}$.

The crystalline phases, the morphologies and chemical compositions of samples were determined by an X-ray diffractometer (Bruker, D8 Advance), a scanning electron microscopy (SEM, HitachiS-4800) equipped with an energy dispersive X-ray spectroscope (EDS) respectively.

\section{RESULTS AND DISCUSSIONS}

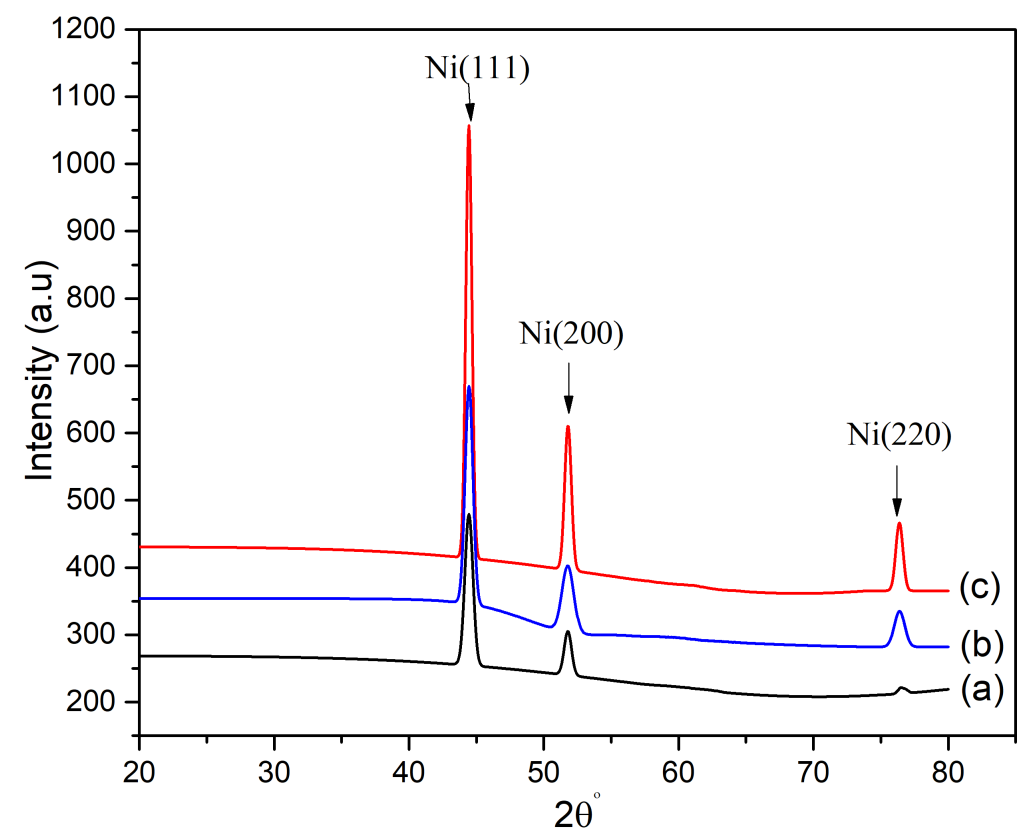

Fig. 1. XRD diffractogram of Ni films deposited with different electrolytic currents: (a) $1 \mathrm{~mA}$; (b) $3 \mathrm{~mA}$; (c) $5 \mathrm{~mA}$.

Figure 1 displays the XRD patterns of Ni films (without annealing) deposited by the electrolyser with the electrolytic currents of $1 \mathrm{~mA}, 3 \mathrm{~mA}$ and $5 \mathrm{~mA}$. The Ni films were crystallized in Ni crystal with the face-centered cubic structure. The intensity of the peaks increased with the increase in the electrolytic currents. It is easy to know that the intensity of XRD peaks is strongly 
dependent on the volume fraction of phase [15]. The thicknesses of the films deposited with current of $1 \mathrm{~mA}$ and $5 \mathrm{~mA}$ are about $150 \mathrm{~nm}$ and $200 \mathrm{~nm}$, respectively (as shown in Fig. 2). The increase in thickness of the Ni films leaded to increases their volume fraction of phase, resulting in the increase of the XRD peak intensity.
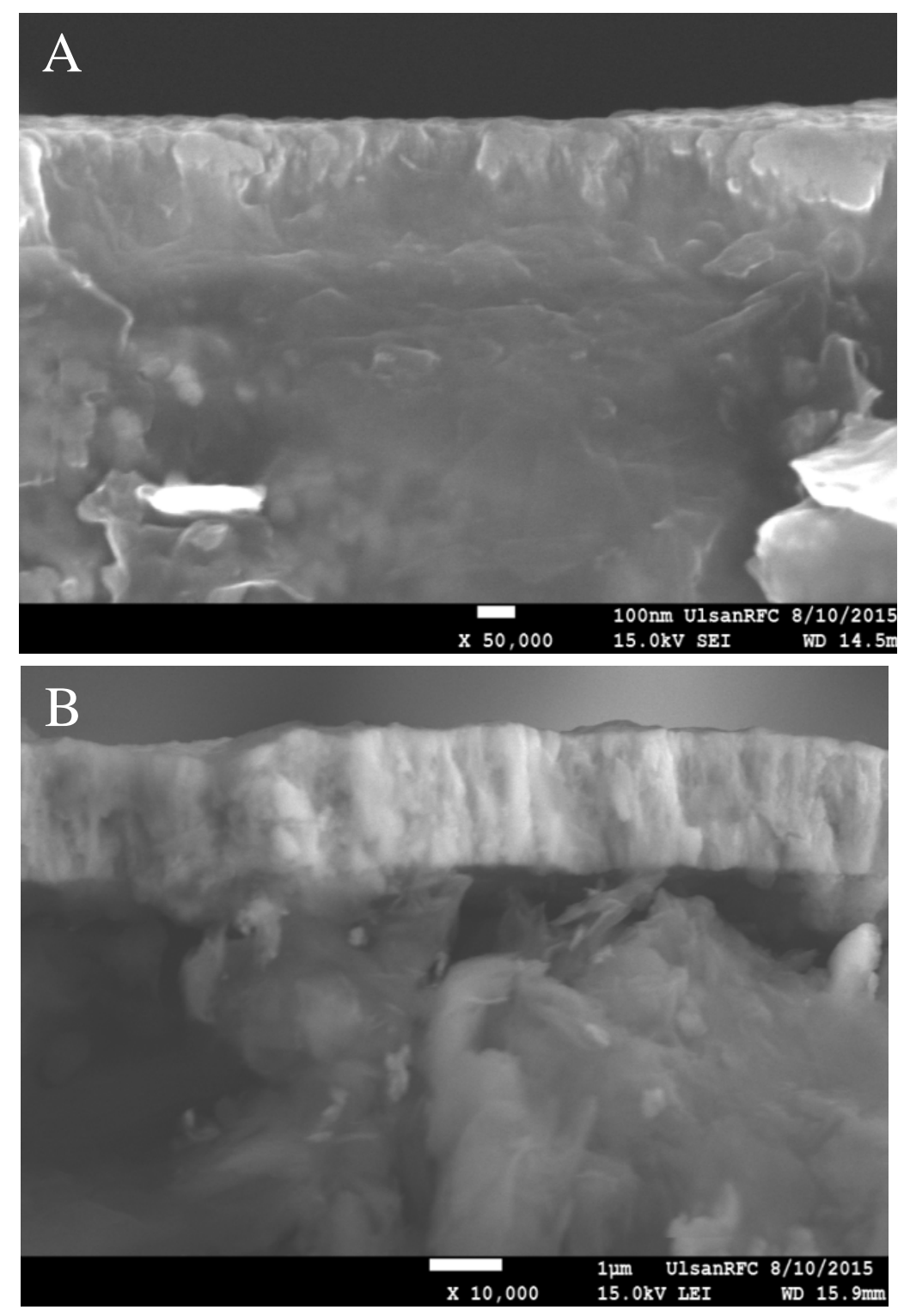

Fig. 2. FE-SEM cross-section images of Ni films deposited with different electrolytic currents: A) $1 \mathrm{~mA}$; B) $5 \mathrm{~mA}$.

Fig. 3A, Fig. 3B and Fig. 3C are FE-SEM images of Ni films deposited with different electrolytic currents. A sample deposited with a higher current showed a lager grain size and 
a higher roughness. For the electrocatalytic purpose, the surface of the films should be rough. Besides, the thickness of the films should be thick to avoid peeling off the films during the reaction with $\mathrm{H}_{2} \mathrm{PtCl}_{6}$. Therefore, the samples deposited with the current of $5 \mathrm{~mA}$ were used for further experiments.
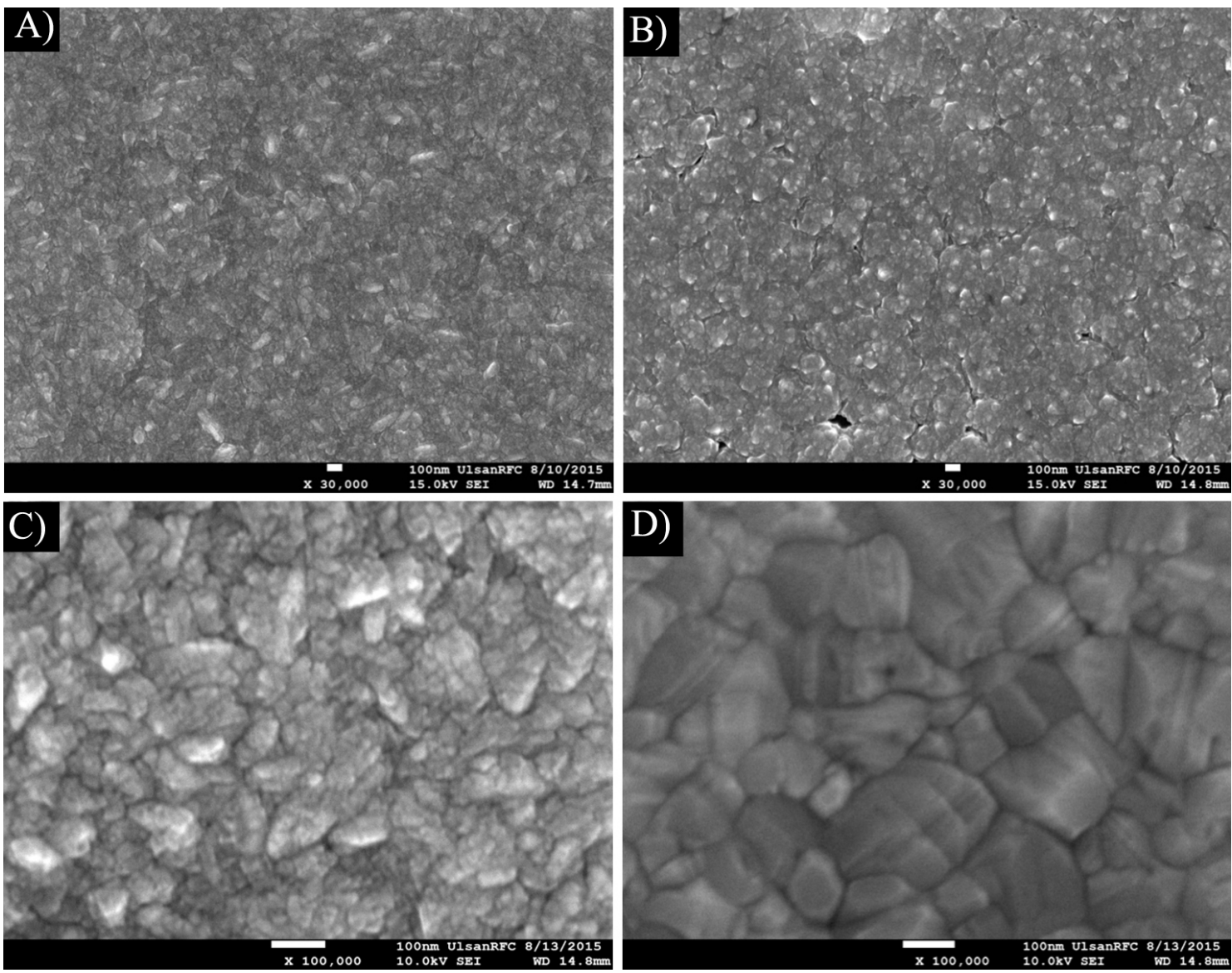

Fig. 3. FE-SEM images of Ni films deposited with different electrolytic currents without annealing (A) $1 \mathrm{~mA}$; (B) $3 \mathrm{~mA}$; (C) $5 \mathrm{~mA}$ and (D) annealing in $\mathrm{H}_{2}$ at $250^{\circ} \mathrm{C}$

Somehow, small amount of nickel oxide remaining on the Ni films could slow down the galvanic reaction. Ni films were consequently purified by annealing in hydrogen at $250^{\circ} \mathrm{C}$ for $1 \mathrm{~h}$ before immersing into $\mathrm{H}_{2} \mathrm{PtCl}_{6}$. The EDX spectra in Fig. 4 showed that the films without annealing have $0.83 \mathrm{Wt} \%$ of oxygen and $99.17 \mathrm{Wt} \%$ of nickel while the annealed films are pure nickel. On the other hand, the FE-SEM image of annealed Ni films (Fig. 3D) showed that, although the annealed sample was not coated by conductive material, their surface morphology is clearer than that of samples without annealing. The amount of nickel oxide left on the surface of samples without annealing blurred their SEM images. 
A)
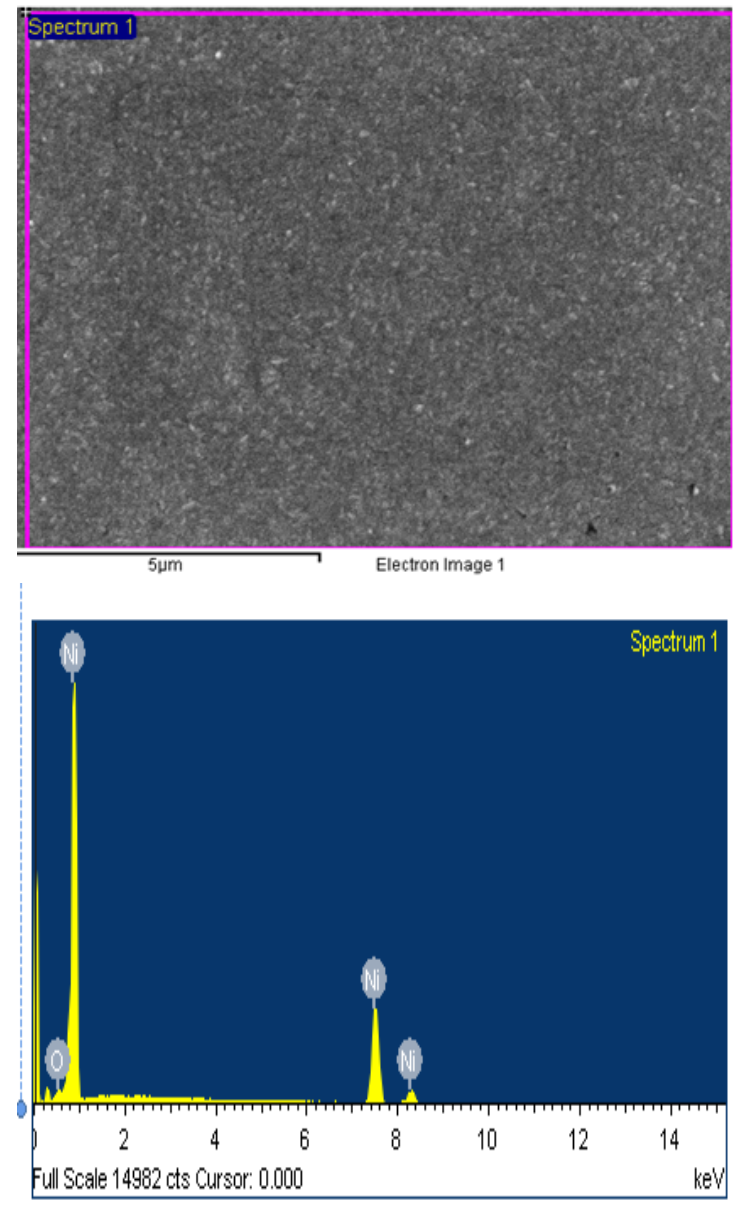

B)
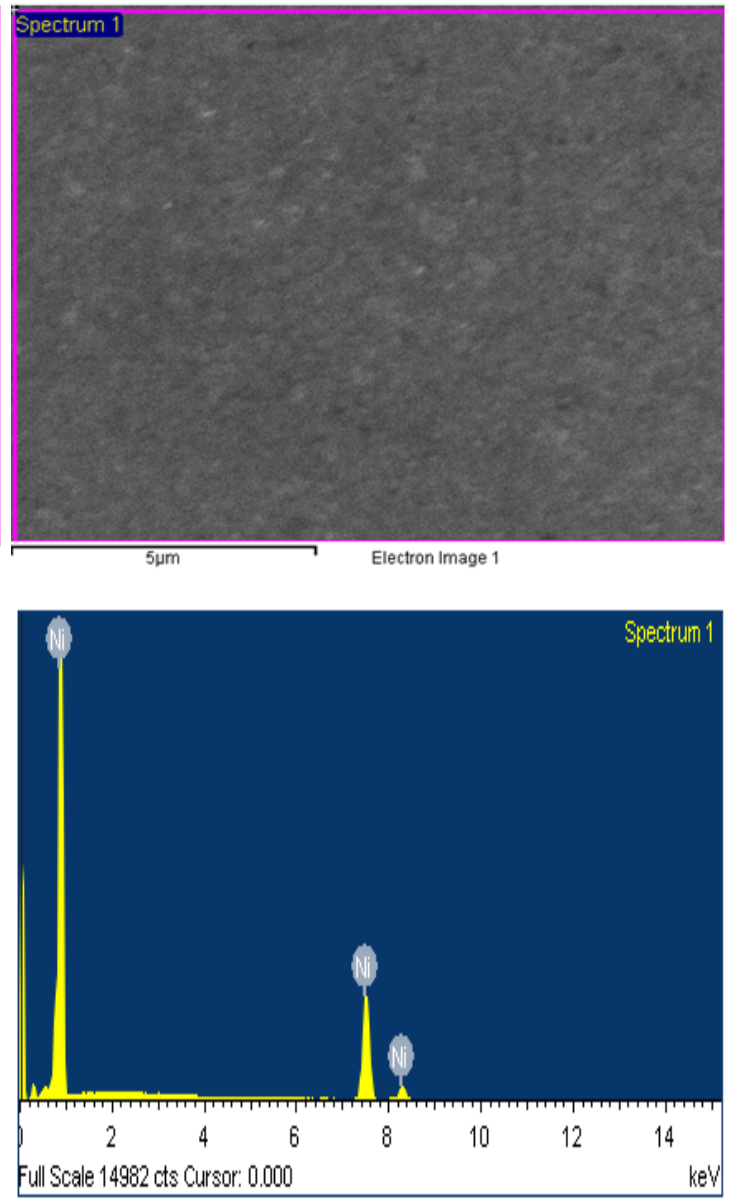

Fig. 4. EDX spectra of Ni films deposited with the current of $5 \mathrm{~mA}$ : A) without annealing; B) annealed in $\mathrm{H}_{2}$ at $250^{\circ} \mathrm{C}$.

The surface morphology of samples immersed in $\mathrm{H}_{2} \mathrm{PtCl}_{6}$ solution is showed in Fig. 5. The average particle size that was estimated is about $100 \mathrm{~nm}$. The surfaces were strongly modified by galvanic replacement reaction due to the following equation:

$$
2 \mathrm{Ni}+\mathrm{H}_{2} \mathrm{PtCl}_{6}=\mathrm{Pt}+2 \mathrm{NiCl}_{2}+2 \mathrm{HCl}
$$

Platinum precipitated on the surface of the films was alloyed with nickel to form NiPt alloys. The composition analysis by EDX was used to evaluate how much platinum and nickel were in the alloys. Fig. 6 is EDX spectra of NiPt alloys that were prepared by immersing Ni films in different $\mathrm{H}_{2} \mathrm{PtCl}_{6}$ solution concentration. The EDX data in Table 1 showed the small amount of oxygen remained in the samples (lesser than $3 \mathrm{Wt} \%$ ). This indicated that a little nickel oxide was formed during galvanic reaction. The ratio of $\mathrm{Pt} / \mathrm{Ni}$ on the alloys increases with the increase 
of $\mathrm{H}_{2} \mathrm{PtCl}_{6}$ concentration. The concentration of $\mathrm{Pt}$ in the samples immersed in $0.1 \mathrm{M} \mathrm{H}_{2} \mathrm{PtCl}_{6}$ is $15.60 \mathrm{Wt} \%$ while it is $33.94 \mathrm{Wt} \%$ for the samples immersed in $0.3 \mathrm{M} \mathrm{H}_{2} \mathrm{PtCl}_{6}$.
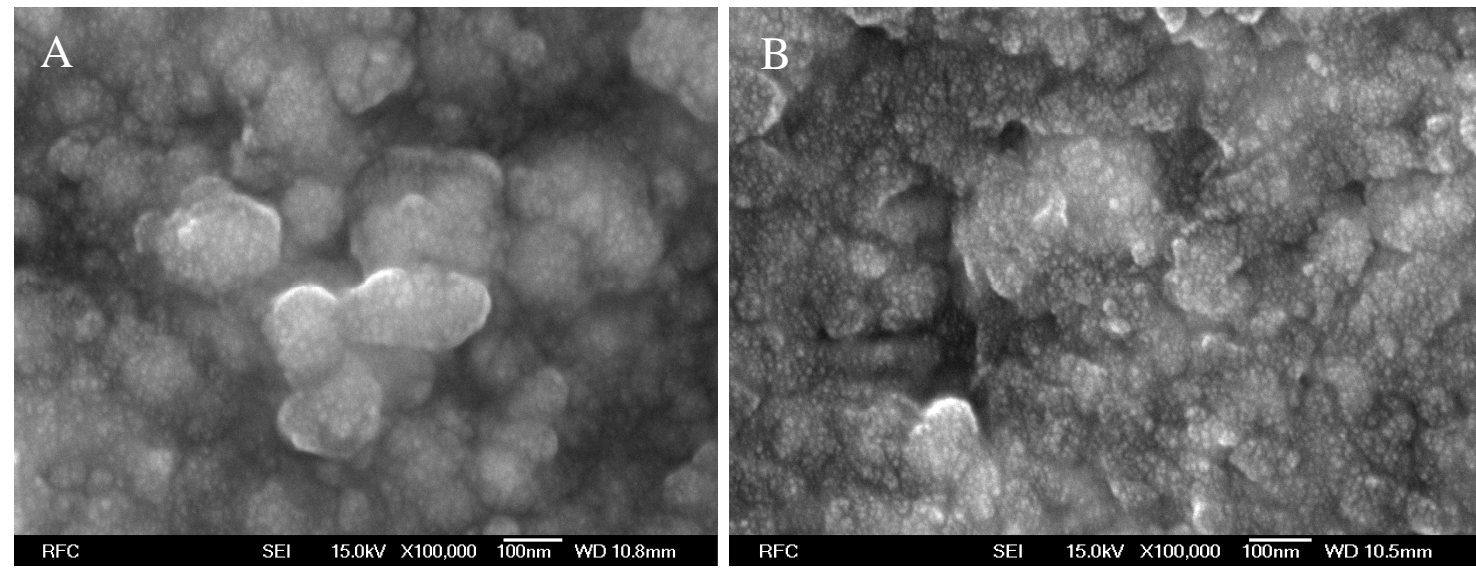

Fig. 5. FE-SEM images of NiPt alloys immersed in different $\mathrm{H}_{2} \mathrm{PtCl}_{6}$ solution contents: A) $0.1 \mathrm{M}$; B) $0.3 \mathrm{M}$.

Table 1. Composition analysis data.

\begin{tabular}{|l|c|c|c|}
\hline Sample & Oxygen $\mathbf{( W t} \%)$ & Platinum $\mathbf{( W t \% )}$ & Nickel ( Wt\%) \\
\hline A & 2.11 & 15.60 & 82.29 \\
\hline B & 2.88 & 33.94 & 63.18 \\
\hline
\end{tabular}

The electrocatalyst activities were determined by cyclic voltammetry measurement in 2.0 $\mathrm{M} \mathrm{KOH}$ and $1.0 \mathrm{M}$ ethanol. The measurement was first carried out with $\mathrm{Ni}$ films and then with NiPt alloys.

Fig. 7A is a cyclic voltammogram (CV) of the Ni film. The oxidations of $\mathrm{Ni}$ are described by the following equations:

The oxidation of $\mathrm{Ni}^{0}$ to $\mathrm{Ni}^{+}$:

$$
\mathrm{Ni}+\mathrm{OH}^{-} \longrightarrow \mathrm{Ni}-\mathrm{OH}_{a d s}+\mathrm{e}^{-}
$$

The oxidation of $\mathrm{Ni}^{+}$to $\mathrm{Ni}^{2+}$ :

$$
\mathrm{Ni}-\mathrm{OH}_{a d s}+\mathrm{OH}^{-} \longrightarrow \mathrm{Ni}(\mathrm{OH})_{2}+\mathrm{e}^{-}
$$

The oxidation of $\mathrm{Ni}^{2+}$ to $\mathrm{Ni}^{3+}$ :

$$
\mathrm{Ni}(\mathrm{OH})_{2} \longrightarrow \mathrm{NiOOH}
$$

The CV peak corresponding to the oxidation of $\mathrm{Ni}^{0}$ to $\mathrm{Ni}^{+}$is not present in the $\mathrm{CV}$ curve because the resolution of instrument. The peak (Fig. 7A) marked by "If " is originated from the oxidation of $\mathrm{Ni}^{+}$to $\mathrm{Ni}^{2+}$ Eq. (3). The peak at $0.35 \mathrm{~V}$ is related to the oxidation of $\mathrm{Ni}^{2+}$ to $\mathrm{Ni}^{3+}$ Eq. (4). 

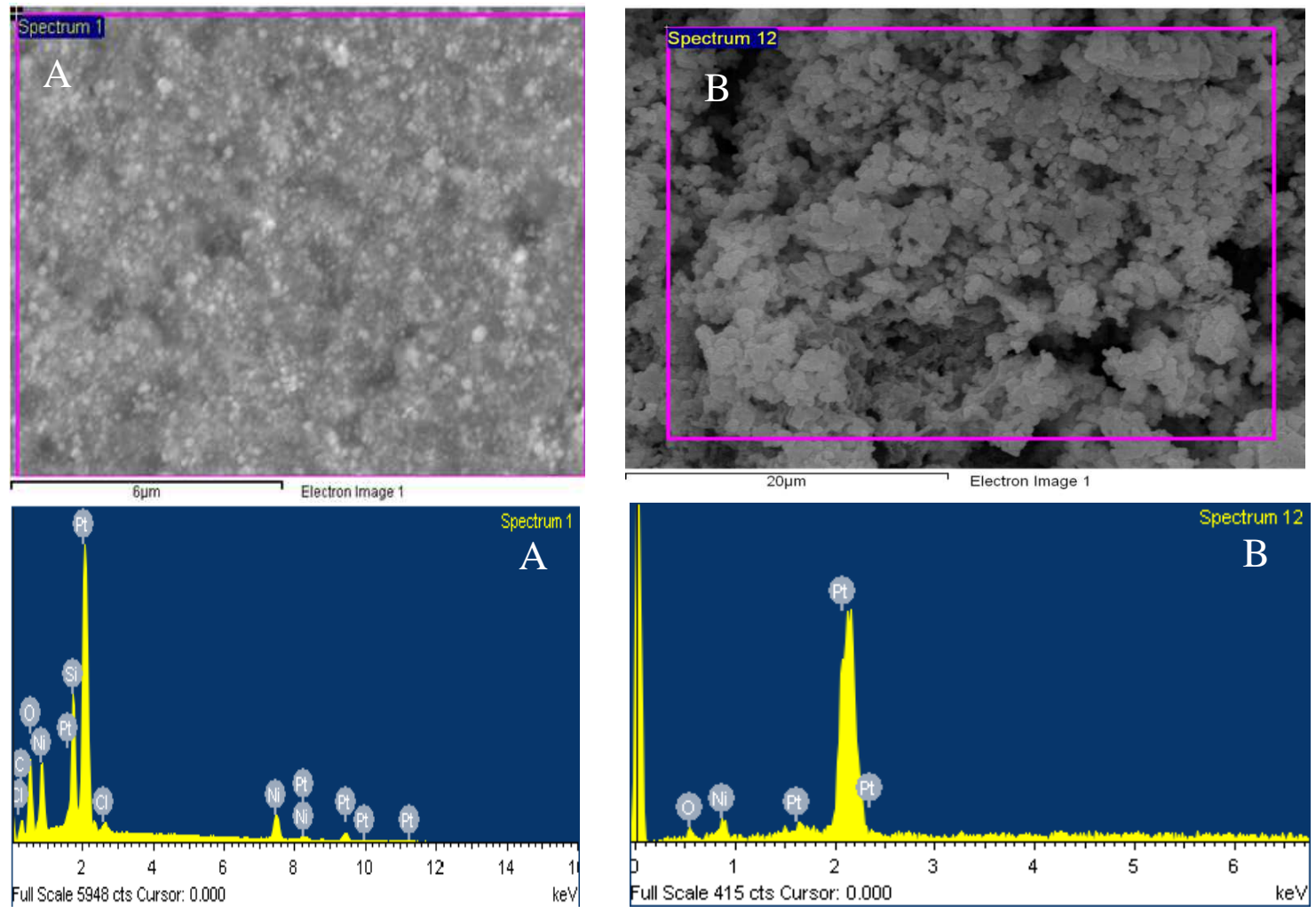

Fig. 6. EDX spectra of NiPt alloys immersed in different $\mathrm{H}_{2} \mathrm{PtCl}_{6}$ solution contents: A) $0.1 \mathrm{M}$; B) $0.3 \mathrm{M}$.

The CV curve of NiPt alloys is described by Fig. $7 \mathrm{~B}$ (curve "a" belongs to the sample immersed in $0.1 \mathrm{M} \mathrm{H}_{2} \mathrm{PtCl}_{6}$; curve "b" belongs to the sample immersed in $0.3 \mathrm{M} \mathrm{H}_{2} \mathrm{PtCl}_{6}$ ).

The presence of the first peak (marked by "I $f$ ") is believed to be ethanol oxidation due to the equations:

$$
\mathrm{C}_{2} \mathrm{H}_{5} \mathrm{OH}+12 \mathrm{OH}^{-} \longrightarrow 2 \mathrm{CO}_{2}+9 \mathrm{H}_{2} \mathrm{O}+12 \mathrm{e}^{-}
$$

or

$$
\mathrm{C}_{2} \mathrm{H}_{5} \mathrm{OH}+\mathrm{H}_{2} \mathrm{O} \longrightarrow \mathrm{CH}_{3} \mathrm{OH}+\mathrm{CO}+4 \mathrm{H}+4 \mathrm{e}^{-} \text {. }
$$

The electrocatalyst activities of $\mathrm{Ni}_{63.18} \mathrm{Pt}_{33.94}$ (curve "b") were better than that of $\mathrm{Ni}_{82.29} \mathrm{Pt}_{15.6}$ (curve a). Platinum acts as the main electrocatalyst in EOR so that the sample with higher platinum concentration should have better ethanol oxidation.

The second peak agrees with the oxidation of $\mathrm{Ni}^{2+}$ to $\mathrm{Ni}^{3+}$ as shown in Fig.7A and Eq. (4). Compared to the ethanol oxidation using pure $\mathrm{Pt}$ wire as electrocatalyst in previous study [14], the ethanol oxidation using NiPt in this study is improved. As mentioned in Eq. (6), the CO generated during the oxidation reaction can be adsorbed by Pt causing the electrode poison. The presence of $\mathrm{NiOOH}$ (see Eq. (4)) removed $\mathrm{CO}_{a d s}$ by the reaction [14]:

$$
\mathrm{Pt}(\mathrm{CO})_{a d s} \longrightarrow \mathrm{Pt}+\mathrm{CO}_{3}^{2-}+2 \mathrm{H}^{+} \text {. }
$$



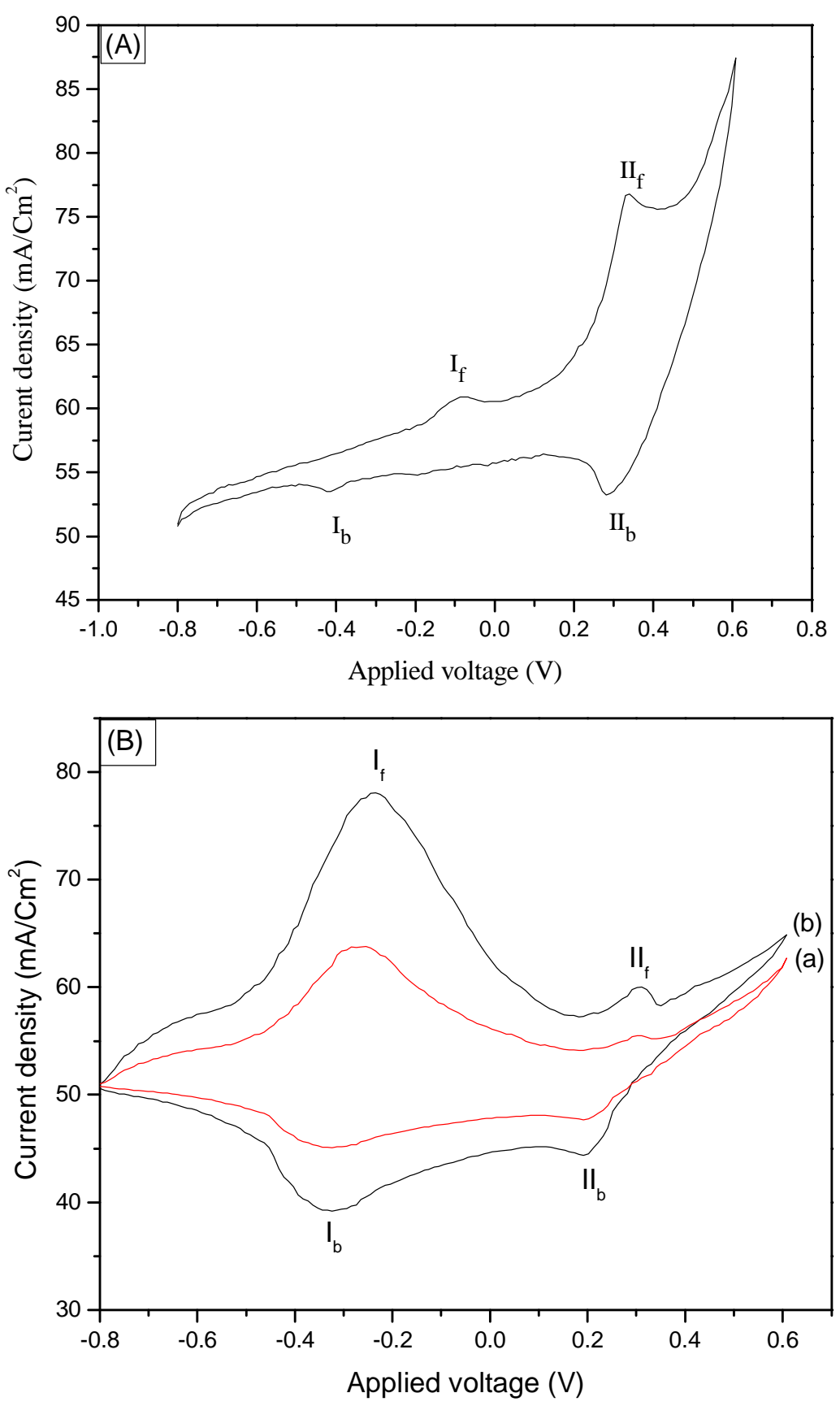

Fig. 7. The cyclic voltammogram carried out in $2 \mathrm{MKOH}$ and $1 \mathrm{M}$ ethanol: A) Ni film; B) NiPt alloys. 
PREPARATION OF NiPt ALLOYS BY GALVANIC REPLACEMENT REACTION ON Ni FIMLS ...

Besides, the presence of $\mathrm{Ni}$ in NiPt alloys results in weakening Pt-CO $\mathrm{Cd}_{s}$ bond. Indeed, $\mathrm{CO}$ absorbed on Pt by sharing their electrons in the $5 \mathrm{~s}$ orbit to Pt and receiving electrons from $\mathrm{d}$ band of Pt contributes to their 2 $\mathrm{p}^{*}$ antibonding orbit [8]. Alloying with $\mathrm{Ni}, \mathrm{Pt}$ should share electrons to $\mathrm{Ni}$ instead of $\mathrm{CO}$ resulting in weakening $\mathrm{Pt}-\mathrm{CO}_{a d s}$ bond. Both removed and weakened $\mathrm{CO}_{a d s}$ speeded up ethanol oxidation.

\section{CONCLUSIONS}

NiPt alloys were successfully prepared by galvanic replacement reaction on nickel films. The SEM images demonstrated that surface morphology of Ni films was modified strongly by galvanic reaction. The average particle size of $\mathrm{NiPt}$ alloys is about $100 \mathrm{~nm}$. The surface composition of $\mathrm{Ni} / \mathrm{Pt}$ in the alloys depended on the concentration of $\mathrm{H}_{2} \mathrm{PtCl}_{6}$ solution. EDX analysis showed that the composition of $\mathrm{Pt}$ were $15.60 \mathrm{Wt} \%$ and $33.94 \mathrm{Wt} \%$ corresponding to the concentration of $\mathrm{H}_{2} \mathrm{PtCl}_{6} 0.1 \mathrm{M}$ and $0.3 \mathrm{M}$, respectively. NiPt alloys exhibited good electrocatalytic activities toward ethanol oxidation in alkaline solution. The improvement of electrocatalytic activities of $\mathrm{NiPt}$ alloys was the results of carbonaceous removal and $\mathrm{Pt}-\mathrm{CO}_{a d s}$ bond weakening due to the presence of nickel.

\section{ACKNOWLEDGMENT}

This research was funded by Vietnam National Foundation for Science and Technology Development (NAFOSTED) under grant number of 103.02-2013.50.

\section{REFERENCES}

[1] Z. Zheng, R. Petrone, M.C. Péra, D. Hissel, M. Becherif, C. Pianese, N. Yousfi Steiner, M. Sorrentino, International Journal of Hydrogen Energy, 38 (2013) 8914-8926.

[2] S. P. S. Badwal, S. Giddey, A. Kulkarni, J. Goel and S.Basu, Applied Energy,145(2015)80-103

[3] Subramanian, Sundarrajan, Suleyman, I.Allakhverdiev, Seeram, Ramakrishna, International Journal of Hydrogen Energy, 37 (2012) 8765-8786.

[4] R.M. Antoniassi, L. Otubo, J.M. Vaz, A. Oliveira Neto, E.V. Spinacé, Journal of Catalysis, 342 (2016) 67-74.

[5] J. Sánchez-Monreal, P.A. García-Salaberri, M. Vera, Journal of Power Sources, 363 (2017) 341-355.

[6] H. Takahashi, M. Sagihara, M. Taguchi, International Journal of Hydrogen Energy, 39 (2014) 18424-18432.

[7] J. Perez, V.A. Paganin, E. Antolini, Journal of Electroanalytical Chemistry, 654 (2011) 108-115.

[8] G. Blyholder, The Journal of Physical Chemistry, 68 (1964) 2772-2777.

[9] D.Y. Chung, M.J. Lee, M. Kim, H. Shin, M.-J. Kim, J.M. Yoo, S. Park, Y.-E. Sung, Catalysis Today, 293 (2017) 2-7.

[10] J.M. Léger, F. Hahn, B. Beden, C. Lamy, M.F. Bento, I. Fonseca, M.I.S. Lopes, Journal of Electroanalytical Chemistry, 356 (1993) 255-267.

[11] J. Maya-Cornejo, R. Carrera-Cerritos, D. Sebastián, J. Ledesma-García, L.G. Arriaga, A.S. Aricò, V. Baglio, International Journal of Hydrogen Energy, 42 (2017) 27919-27928.

[12] K. Ding, Y. Zhao, L. Liu, Y. Cao, Q. Wang, H. Gu, X. Yan, Z. Guo, International Journal of Hydrogen Energy, 39 (2014) 17622-17633.

[13] T.S. Almeida, L.M. Palma, P.H. Leonello, C. Morais, K.B. Kokoh, A.R. De Andrade, Journal of Power Sources, 215 (2012) 53-62.

[14] V.V. Pham, V.-T. Ta, C. Sunglae, International Journal of Hydrogen Energy, 42 (2017) 13192-13197.

[15] L.E. Alexander, H.P. Klug, Analytical Chemistry, 20 (1948) 886-894. 